\title{
SUPERAÇÃO DA DORMÊNCIA DE SEMENTES DE TRÊS ESSÊNCIAS FLORESTAIS NATIVAS
}

\author{
Roberto ANDREANI JUNIOR ${ }^{1}$ \\ Wellington dos Santos de MELLO ${ }^{2}$ \\ Sérgio Roberto Garcia dos SANTOS ${ }^{3}$ \\ Dora Inés KOZUSNY-ANDREANI ${ }^{4}$
}

\author{
${ }^{1}$ Prof. Dr, Univ.Camilo Castelo Branco, robertoandreani@uol.com.br. \\ ${ }^{2}$ Eng. Florestal, Univ.Camilo Castelo Branco, wellingtonpba@hotmail.com \\ ${ }^{3}$ Pesq. Cient., Instituto Florestal, escunagarcia@if.sp.gov.br \\ ${ }^{4}$ Prof $^{\mathrm{a}}$. Dra ${ }^{\mathrm{a}}$, Univ.Camilo Castelo Branco, doraines@terra.com.br
}

Recebido em: 22/05/2014 - Aprovado em: 30/06/2014 - Disponibilizado em: 30/07/2014

\begin{abstract}
RESUMO: O objetivo deste estudo foi testar vários tratamentos para a superação da dormência em sementes de: guapuruvu (Schizolobium parahyba), tamboril (Enterolobium contortisiliquum) e óleo copaíba (Copaifera langsdorffii). Os tratamentos testados foram: testemunha; escarificação mecânica; escarificação térmica (imersão em água a $100{ }^{\circ} \mathrm{C}$ ); imersão em água em temperatura ambiente; escarificação química através do uso de ácidos sulfúrico e clorídrico, acetona e éter. Os tratamentos testados variaram entre as espécies estudadas. Os ensaios utilizaram a temperatura de $26{ }^{\circ} \mathrm{C}$, com 16 horas de luz e a semeadura das sementes foi sobre areia. Após a análise estatística foi possível afirmar que os melhores resultados para a superação da dormência de sementes do guapuruvu foram as escarificações mecânica, térmica (imersão em água inicialmente a $100{ }^{\circ} \mathrm{C}$ durante 20 minutos) e química (ácido sulfúrico por 30 minutos); para o tamboril foram os tratamentos de escarificação mecânica e do ácido sulfúrico por 30 e 60 minutos e para o óleo copaíba os maiores valores médios de germinação foram obtidos com o tratamento utilizando ácido sulfúrico por 10 minutos.
\end{abstract}

Palavras-chave: tratamentos pré-germinativos. germinação. escarificação. métodos alternativos. produção de mudas.

\section{OVERCOMING THE SEEDS OF THREE DORMANCY NATIVE FOREST SPECIES}

\begin{abstract}
The aim of this study was to test various treatments to overcome dormancy in seeds : guapuruvu (Schizolobium parahyba), tamboril (Enterolobium contortisiliquum) and copaiba oil of (Copaifera langsdorffii). The treatments were: control; mechanical scarification; thermal scarification (soaking in water at $100{ }^{\circ} \mathrm{C}$ ); immersion in water at room temperature; chemical scraping through the use of sulfuric and hydrochloric acid, acetone and ether. The treatments tested varied among species. The trials used a temperature of $26^{\circ} \mathrm{C}$, with 16 hours of light and sowing of seeds was on sand. After statistical analysis was possible to say that the best results for overcoming seed dormancy of guapuruvu were mechanical, thermal scarification (soaking in water initially at $100^{\circ} \mathrm{C}$ for 20 minutes) and chemical (sulfuric acid for 30 minutes); anglerfish treatments were chiseling and sulfuric acid for 30 to 60 minutes for the oil of copaiba the highest mean germination values were obtained with treatment using sulfuric acid for 10 minutes.
\end{abstract}

Keywords: pre-germination treatments. germination. scarification. alternative methods. seedling production.

\section{INTRODUÇÃO}

Nos últimos anos tem se intensificado o interesse na multiplicação de espécies florestais nativas, devido à ênfase atual para

os problemas ambientais, ressaltando-se a necessidade de recuperação de áreas 
degradadas e recomposição da paisagem. Entretanto, não há conhecimento disponível para o manejo e análise das sementes da maioria dessas espécies, de modo a fornecer dados que possam caracterizar seus atributos físicos e fisiológicos. Há, também, necessidade de se obterem informações básicas sobre a germinação, cultivo e potencialidade dessas espécies nativas, visando sua utilização para os mais diversos fins (AGUIAR et. al., 1993; ZANON et. al., 1997; ARAUJO NETO et al., 2003).

Procurando atender estas demandas oriundas dos trabalhos de recuperação de áreas degradas e recomposição da paisagem, a produção de mudas de espécies nativas enfrenta o problema de dormência de sementes de muitas espécies que causam atrasos no desenvolvimento da planta, sendo esta uma característica considerada como fator limitante (NEGRI et al., 2008).

Esta dificuldade que a produção de mudas enfrenta através da dormência ocorre em algumas espécies, de acordo com Carvalho e Nakagawa (2000), por que as suas sementes mesmo sendo viáveis e tendo todas as condições ambientais para tanto, não germinam. Este fenômeno, que apresenta diferentes intensidades, distribui a germinação das sementes no tempo. Sendo que a dormência ocorre devido a fatores como impermeabilidade do tegumento à água e à troca de gases, embriões fisiologicamente imaturos ou rudimentares, presença de substâncias promotoras ou inibidoras de crescimento e exigências diferenciadas de luz e temperatura.

Assim, embora a dormência seja vantajosa para aumentar as chances de sobrevivência da espécie na natureza, este fenômeno pode se tornar um problema quando se pretende produzir mudas em viveiro, em razão do atraso e desuniformidade na germinação das sementes. Concomitantemente, diante da enorme biodiversidade do Brasil, existem poucas informações sobre as espécies nativas quanto as suas formas de propagação. (MARANHO; PAIVA, 2012)

Deste modo o uso de métodos (físicos e químicos) na superação da dormência de sementes são importantes para viabilizar a produção de mudas e este trabalho teve por objetivo testar a eficiência de alguns deles em sementes de três essências florestais nativas: guapuruvu (Schizolobium parahyba); tamboril (Enterolobium contortisiliquum) e óleo copaíba (Copaifera langsdorffii), que apresentam impermeabilidade do tegumento (AZEREDO et al., 2003; PEREIRA et al., 2007).

\section{MATERIAL E MÉTODOS}

O experimento foi conduzido no laboratório de biotecnologia da Universidade Camilo Castelo Branco - UNICASTELO, campus de Fernandópolis/SP, utilizando sementes doadas pela Flora Tietê localizada em Penápolis/SP. As espécies estudadas foram: guapuruvu [Schizolobium parahyba (Vell.) Blake]; 
tamboril [Enterolobium contortisiliquum (Vell.) Morang] e óleo copaíba [Copaifera langsdorffii (Desf.)].

As sementes das três espécies foram dispostas em gerbox contendo como substrato areia grossa. Cada tratamento teve quatro repetições. Após a semeadura, foi colocado em média $60 \mathrm{ml}$ de água por gerbox e utilizou-se o fungicida "Nistatina" junto com a água para a diminuição de ocorrência de fungos. Os gerbox foram colocados em câmaras de germinação de alvenaria por 21 dias em temperatura de $26{ }^{\circ} \mathrm{C}$ com 16 horas de luz. Foram utilizadas por tratamento para cada espécie, 80 sementes de tamboril (Enterolobium contortisiliquum); 40 sementes de guapuruvu (Schizolobium parahyba) e 80 sementes de óleo copaíba (Copaifera langsdorffii).

Para as sementes de guapuruvu foram testados cinco tratamentos de superação da dormência e mais a testemunha. Nos dois tratamentos com água quente, esta foi aquecida em um forno de micro-ondas até atingir o seu ponto de fervura $\left(100{ }^{\circ} \mathrm{C}\right)$, em seguida as sementes foram colocadas em béquer, permanecendo por 10 minutos em embebição (durante a queda de temperatura deste liquido) representando um tratamento e 20 minutos no outro tratamento (com o mesmo procedimento). No tratamento de escarificação mecânica, fez-se uso de uma lixa $\mathrm{n}^{\circ} 80$ para raspar o tegumento da semente. No tratamento com ácido sulfúrico $\left(\mathrm{H}_{2} \mathrm{SO}_{4}\right)$, as sementes foram colocadas em um béquer e depois foi adicionado o respectivo ácido que permaneceu por 30 minutos sobre as sementes. Em seguida as sementes são retiradas do béquer e colocadas em água corrente por 15 minutos para a lavagem dos resíduos do ácido. No tratamento com o ácido clorídrico $(\mathrm{HCl})$, este foi derramado dentro de um béquer onde estavam as sementes, que permaneceram nesta solução por 30 minutos, em seguida as sementes foram retiradas e mantidas sob água corrente por 15 minutos. No tratamento testemunha, as sementes foram colocadas para germinar sem nenhum tratamento prévio.

Nas sementes de tamboril foram realizados seis tratamentos. No tratamento de escarificação mecânica, fez-se uso de uma lixa $\mathrm{n}^{\mathrm{o}} \quad 80$ nas sementes, raspando o tegumento. Nos dois tratamentos com ácido sulfúrico, este foi derramado em dois béqueres contendo as sementes, e estas ficaram imergidas durante períodos diferentes, 30 e 60 minutos, em cada tratamento. Em seguida, as sementes foram retiradas dos béqueres e lavadas em água corrente por 15 minutos para a eliminação dos resíduos do ácido sulfúrico sobre o tegumento. No tratamento com água quente, esta foi aquecida em um forno de micro-ondas até atingir o seu ponto de ebulição $\left(100{ }^{\circ} \mathrm{C}\right)$, quando então as sementes foram colocadas no béquer, e permaneceram por 3 minutos na água; no outro tratamento, com o mesmo procedimento adotado, as sementes após a imersão na água (em ebulição) permaneceram 
no frasco até o resfriamento da mesma. No tratamento testemunha, as sementes foram colocadas a germinar sem nenhum tratamento prévio.

Para as sementes de óleo copaíba foram realizados cinco tratamentos. No tratamento com éter $\left(\mathrm{C}_{4} \mathrm{H}_{10} \mathrm{O}\right)$, este foi derramado em um béquer contendo as sementes, onde estas ficaram imersas durante 20 minutos. No tratamento com ácido sulfúrico, este foi derramado em um béquer contendo as sementes, onde estas ficaram imergidas durante 10 minutos. No tratamento com acetona $\left(\mathrm{C}_{3} \mathrm{H}_{6} \mathrm{O}\right)$, esta foi derramada em um béquer contendo as sementes, e mantendo a substância no frasco durante 20 minutos. Em todos os tratamentos, após a retirada das sementes dos frascos, estas foram lavadas em água corrente por 15 minutos para a eliminação dos resíduos destas substâncias químicas. No tratamento de imersão em água à temperatura ambiente por 48 horas, as sementes foram colocadas em um béquer com água permanecendo em seu interior neste período de tempo. No tratamento testemunha, as sementes foram colocadas a germinar sem nenhum tratamento prévio.

Todos os experimentos foram montados seguindo o delineamento estatístico inteiramente casualizado (DIC). Foi realizada a contagem das sementes que germinaram a cada três dias. Após 21 dias, o ensaio foi encerrado e os resultados foram submetidos à análise de variância e os mesmos comparados pelo teste de Tukey a 5\% de probabilidade.

\section{RESULTADOS E DISCUSSÃO}

O início da emergência das sementes de Schizolobium parahyba ocorreu em média quatro dias após instalação do ensaio e nas sementes desta espécie os melhores resultados de porcentagem de germinação (Figura 1), foram obtidos com os tratamentos que utilizaram a escarificação mecânica, o ácido sulfúrico por 30 minutos e a água quente $\left(100{ }^{\circ} \mathrm{C}\right)$ com sementes imersas durante 20 minutos.

Figura 1 - Valores médios de porcentagem de germinação de sementes de guapuruvu (Schizolobium parahyba) submetidas à diferentes métodos de superação da dormência.

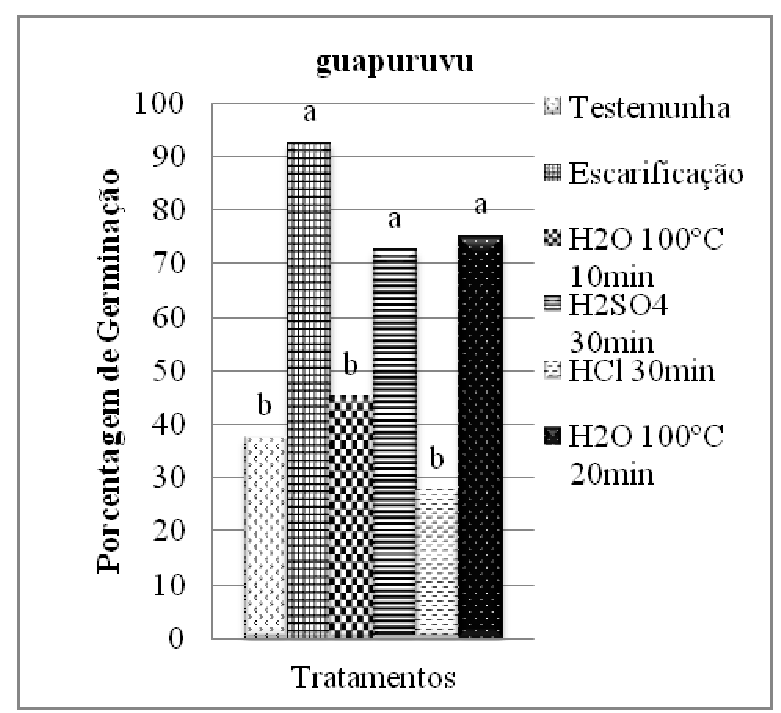

Fonte- Universidade Camilo Castelo Branco, campus Fernandópolis. 2014.

Neste estudo observou-se que quando aumentou-se o tempo de imersão de 10 para 20 minutos em água quente $\left(100{ }^{\circ} \mathrm{C}\right)$, a resposta germinativa melhorou significativamente. A escarificação física realizada com água a altas temperaturas, entre 60 e $100{ }^{\circ} \mathrm{C}$, tem sido aplicada visando à 
quebra da dormência de várias sementes de leguminosas, sendo que este método apresenta baixo custo (OLIVEIRA, 2007; SILVA et al., 2011). Para Bianchetti e Ramos (1981), os períodos de imersão de 4 a 10 minutos em água fervente $\left(95^{\circ} \mathrm{C}\right)$, deixando as sementes na mesma água, fora do aquecimento, por 48 horas, podem ser usados para superar a impermeabilidade do tegumento de sementes de Schizolobium parahyba, enquanto que o estudo de Davide e Silva (2008) recomenda para esta espécie, ferver a água e depois colocar as sementes, deixando-as por 24 horas (nesta água) antes da semeadura.

Os resultados apresentados pela escarificação mecânica confirmam os obtidos por outros autores como Azeredo et al. (2003), Pereira et al. (2011) e Shimizu et al. (2011) os quais constataram que o uso desta técnica, com o emprego de lixa, mostrou-se eficiente para a germinação do $S$. parahyba.

Para um mesmo tempo de embebição da semente, o ácido sulfúrico apresentou uma germinação superior estatisticamente á obtida pela semente embebida no ácido clorídrico. Em outros estudos de quebra de dormência com sementes de espécies nativas, que testaram na mesma pesquisa, os ácidos clorídrico e sulfúrico, os resultados obtidos foram diferenciados. Mantoan et al. (2012) utilizou os dois ácidos em sementes de Adenanthera pavonina, sendo que o ácido sulfúrico mostrou-se eficiente para um tempo de imersão de 30 minutos, mas não para 40 minutos; para o ácido clorídrico os resultados foram inferiores, para os mesmos tempos de imersão (30 e 40 minutos) comparativamente aos obtidos com o ácido sulfúrico. Para Pereira et al. (2011), os resultados com estes dois ácidos (clorídrico e sulfúrico) foram equivalentes e não foram considerados eficientes como os tratamentos para superar a dormência de sementes de Schizolobium parahyba.

Os tratamentos que apresentaram maior porcentagem de germinação das sementes de Enterolobium contortisiliquum foram aqueles cuja quebra de dormência foi por escarificação mecânica e a imersão em ácido sulfúrico por 30 e 60 minutos (Figura 2).

Figura 2 - Valores médios da porcentagem de germinação de sementes de tamboril (Enterolobium contortisiliquum) submetidas à diferentes métodos de superação da dormência.

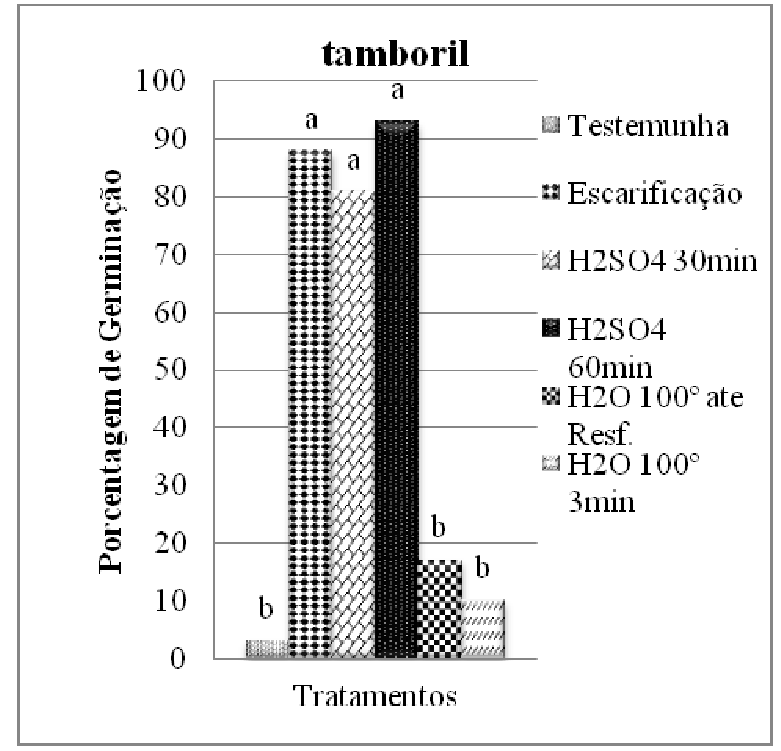

Fonte- Universidade Camilo Castelo Branco, campus Fernandópolis. 2014. 
O uso de ácido sulfúrico para a quebra da dormência de sementes de $E$. contortisiliquum foi eficiente também em outras pesquisas, pois autores, como Vieira e Fernandes (1997) indicam a imersão no ácido sulfúrico por 90 minutos junto com a escarificação mecânica e Fowler e Bianchetti (2000) recomendam a imersão em $\mathrm{H}_{2} \mathrm{SO}_{4}$ (75\%) por 30 minutos, seguida de lavagem em água corrente.

O tratamento com escarificação mecânica utilizado na superação da dormência de sementes de E. contortisiliquum também foi eficiente conforme comprovaram os estudos de Alexandre et al. (2009) e CruzSilva e Rosa (2011).

No ensaio para superação da dormência das sementes de Copaifera langsdorffii se destacou, em valores médios de germinação (Figura 3), o tratamento que utilizou o ácido sulfúrico por 10 minutos, mas este não diferiu estatisticamente dos tratamentos: éter por 20 minutos, acetona por 20 minutos e testemunha.

Perez et al.(1993) em estudo de superação da dormência com sementes de óleo copaíba concluíram que os tratamentos: imersão em acetona por 20 minutos, imersão em éter por 20 minutos e imersão em ácido sulfúrico por 10 minutos são equivalentes estatisticamente e estão entre os melhores testados, para valores de percentagem e velocidade de germinação.
Figura 3 - Valores médios da porcentagem de germinação de sementes de óleo copaíba (Copaifera langsdorffii) submetidas à diferentes métodos de superação de dormência.

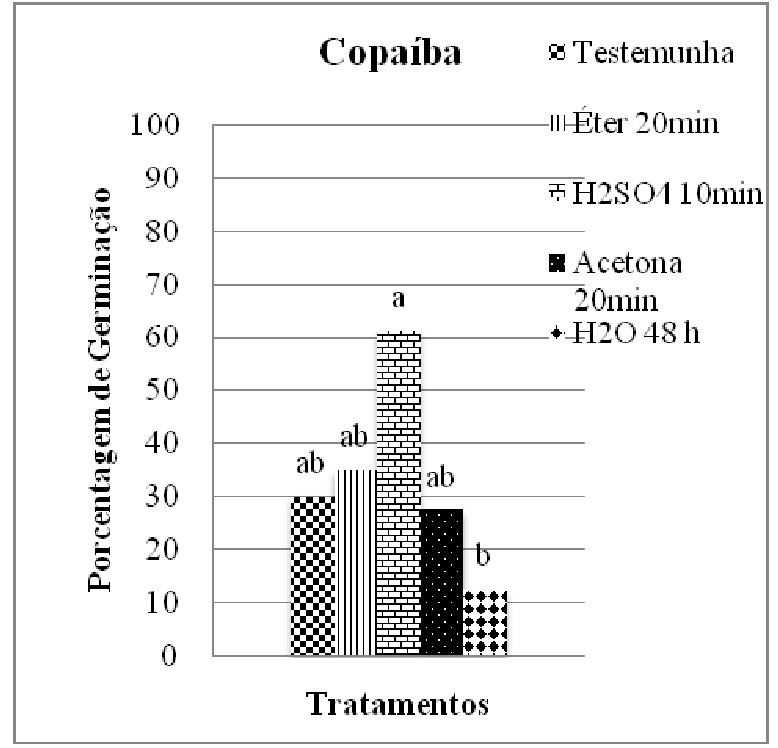

Fonte- Universidade Camilo Castelo Branco, campus Fernandópolis. 2014.

As sementes de Copaifera langsdorffii apresentam dormência ocasional que pode ser superada por diversos métodos: imersão em água fria por 18 a 72 horas; imersão em ácido sulfúrico $98 \%$ por três a dez minutos; escarificação mecânica (com lixa, areia ou pedras de carboneto de silício); imersão em éter por 20 minutos e estratificação em areia úmida por 15 dias (BORGES et al., 1982; BEZERRA et al., 2002).

A imersão em acetona foi eficiente para superar a dormência em espécie florestal como a faveira (Dimorphandra mollis) cujas sementes foram imersas nesta substância durante 20 minutos (SCALON et al., 2007), mas para a superação da dormência em sementes de tamboril, em trabalho de Cruz- 
Silva e Rosa (2011), este tratamento não foi eficiente, para períodos entre 5 e 30 minutos.

Deste modo, o presente estudo procurou testar diferentes tratamentos de superação da dormência, que são reconhecidamente eficientes (OLIVEIRA, 2007), quando a causa é a impermeabilidade do tegumento e verificou-se que dois deles, o ácido sulfúrico e a raspagem do tegumento com lixa apresentaram bons resultados, o primeiro nas três espécies pesquisadas e o segundo para Schizolobium parahyba e Enterolobium contortisiliquum em razão de uma melhor escarificação do tegumento. Estes resultados confirmam a observação de Zaidan e Barbedo (2004), pois, segundo estes autores para este tipo de dormência deve-se priorizar métodos que promovam a embebição das sementes.

É importante lembrar que a diferenciação entre os resultados obtidos por este estudo e os outros, para a mesma espécie, pesquisando tratamentos de quebra da dormência em sementes pode ter relação com a observação feita por Eira et al. (1993), pois segundo estes autores, os tratamentos para a quebra da dormência podem ter uma resposta diferenciada, para sementes de diversas procedências, que revelam assim uma variação no grau de dormência, ou seja, dificultam a indicação da melhor metodologia para superá-la. Deste modo a indicação (e o estudo) de métodos de superação da dormência de sementes florestais levando em consideração o local de origem das espécies é importante para um melhor resultado do tratamento utilizado.

\section{CONCLUSÕES}

Os melhores tratamentos foram: a) Schizolobium parahyba (guapuruvu): escarificação mecânica, imersão em ácido sulfúrico durante 30 minutos e imersão em água quente (inicialmente a $100{ }^{\circ} \mathrm{C}$ ) durante 20 minutos; b) Enterolobium contortisiliquum (tamboril): escarificação mecânica e a imersão em ácido sulfúrico por 30 e 60 minutos e c) Copaifera langsdorffii (copaíba): imersão em ácido sulfúrico por 10 minutos, imersão em éter por 20 minutos, imersão em acetona por 20 minutos e testemunha.

\section{REFERÊNCIAS}

AGUIAR, I.B.; PIÑA-RODRIGUES, F.C.M.; FIGLIOLIA, M.B. Sementes Florestais Tropicais, ABRATES, Brasília, 350p. 1993.

ALEXANDRE, R.S.; GONÇALVES, F.G.; ROCHA, A.P.; ARRUDA, M.P.; LEMES, E.Q. Tratamentos físicos e químicos na superação de dormência de Enterolobium contortisiliquum (Vell.) Morong. Revista Brasileira de Ciências Agrárias, Recife, v.4, n.2, p. 156-159, 2009.

ARAÚJO NETO, J.C.; AGUIAR, I.B.;

FERREIRA, V.M. Efeito da temperatura e da luz na germinação de sementes de Acacia polyphylla DC. Revista Brasileira de 
Botânica. São Paulo, v. 26, n. 2, p. 249-256. 2003.

AZEREDO, G.A.; BRUNO, R.L.A.;

ANDRADE, L.A.; CUNHA, A.O.

Germinação em sementes de espécies

florestais da Mata Atlântica (Leguminoseae)

sob condições de casa de vegetação. Pesquisa

Agropecuária Tropical, Goiânia, v. 33, n.1,

p. 11-16, 2003.

www.revistas.ufg.br/index.php/pat/article/vie

$\underline{\mathrm{w} / 2381 / 2362}$

BEZERRA, A.M.E.; MEDEIROS-FILHO, S.;

MOREIRA, M.G.; MOREIRA F.G.C.;

ALVES, T.T.L.A. Germinação e

desenvolvimento de plântulas de copaíba em

função do tamanho e da imersão da semente

em ácido sulfúrico. Revista Científica

Agronômica, v. 33, n. 2, p.5 - 12, 2002.

http://www.ccarevista.ufc.br/site/artigos_lista.

php?sel $=2002 \&$ sel $2=2 \&$ sel $3=33$

BIANCHETTI, A.; RAMOS, A. Quebra de dormência de sementes de guapuruvu

(Schizolobium parahyba (Vellozo) Blake).

Boletim Pesquisa Florestal, Curitiba, n. 3, p. 69-76,1981.

BORGES, E.E.L.; BORGES, R.C.G.;

CANDIDO, J.F.; GOMES, J.M. Comparação

de métodos de quebra de dormência em sementes de copaíba. Revista Brasileira de

Sementes, v.4, n.1, p.9-12, 1982. http://www.abrates.org.br/revista/artigos/1982

/v4n1/artigo01.pdf

CARVALHO, N.M.; NAKAGAWA, J.

Sementes: ciência, tecnologia e produção.

4.ed. Jaboticabal: Funep, 2000. 588p.

CRUZ-SILVA, C.T.A.C.; ROSA, A.P.M.

Tratamentos para superação da dormência em sementes de orelha-de-negro (Enterolobium contortisiliquum (Vell.) Morong). Revista Varia Scientia Agrárias, v.2, n.2, p.79-

90,2011. e-

revista.unioeste.br/index.php/variascientiaagr $\underline{\text { aria/article/.../5047 }}$

DAVIDE, A.C.; SILVA, E.A.A. Produção

de sementes e mudas de espécies florestais.

Lavras: Ed. UFLA, 2008. 175 p.

EIRA, M.T.S.; FREITAS, R.W.A.; MELLO, C.M.C. Superação da dormência de sementes de Enterolobium contorsiliquum (Vell.)

Morong -LEGUMINOSAE. Revista

Brasileira de Sementes, v. 15, n. 2, p. 177-

$181,1993$.

FOWLER, J. A. P.; BIANCHETTI, A.

Dormência em sementes florestais.

Colombo: EMBRAPA-Florestas, doc. 40, 2000. 27 p.

MARANHO A.S.; PAIVA, A.V. Superação

de dormência tegumentar em sementes de Senna silvestris (Vell.) H. S. Irwin \& 
Barneby. Revista Biotemas, Rio Branco, v.25, n.2, p. 25-31, 2012.

MANTOAN, P.; SOUZA-LEAL, T.; PESSA, H.;MARTELINE, M.A.; PEDROSO-DE-

MORAES, C. Escarificação mecânica e química na superação de dormência de Adenanthera pavonina L.

(Fabaceae:Mimosoideae). Scientia Plena,

Aracaju, v.8, n.5, p.1-8,2012.

http://www.scientiaplena.org.br/ojs/index.php

$\underline{\text { /sp/article/viewFile/100/486 }}$

NEGRI, L.C.G.; ROSA, A.F; ZONETTI, P.C. Quebra de dormência de sementes de espécies arbóreas. IV Mostra Interna de Trabalhos de Iniciação Científica do Cesumar. Maringa (PR). Anais..., 2008.

http://www.cesumar.br/prppge/pesquisa/mostr as/qua mostra/Anderson_Ferreira Rosa.pdf

\section{OLIVEIRA, O. Tecnologia de sementes}

florestais. Curitiba: Imprensa Universitária, 2007. 185p.

PEREIRA, R.S.; RANAL, M.A.; DORNELES, M.C.; SANTANA, D.G.; FREITAS BORGES, K.C.F,; CARVALHO, M.P.L. Emergência de plântulas de Copaifera langsdorffii Desf. Revista Brasileira de Biociências, v. 5, n. S2, p. 1005-1007, 2007. http://www.ufrgs.br/seerbio/ojs/index.php/rbb /article/view/817/689
PEREIRA, M.O.; LEAL, T.S.; LAGAZZI, G.; MORAES, C.P. Avaliação de métodos de escarificação na superação de dormência de Schizolobium parahyba (Vell.) Blake (FABACEAE: CAESALPINIOIDEAE).

Revista em Agronegócios e Meio Ambiente, Araraquara, v.4, n.1, p. 119-129, 2011. http://www.cesumar.br/pesquisa/periodicos/in dex.php/rama/article/view/1852/1189

PEREZ, S.C.J.G.A.; PRADO, C.H.B.A. Efeitos de diferentes tratamentos prégerminativos e da concentração de alumínio no processo germinativo de sementes de Copaifera langsdorffii Desf. Revista

Brasileira de Sementes. Campinas, v.15, n.1, p.115-118,1993.

http://www.abrates.org.br/revista/artigos/1993 /v15n1/artigo19.pdf

SCALON, S.P.Q.; SCALON-FILHO, H.; MUSSURY, R.M.; MACEDO, M.C.;

KISSMANN, C. Potencial germinativo de sementes Dimorphandra mollis Benth. em armazenamento, tratamentos pré-germinativos e temperatura de incubação. Cerne, Lavras, v. 13, n. 3, p.321-328, 2007.

http://www.redalyc.org/pdf/744/74413310.pdf

SHIMIZU, E.S.C.; PINHEIRO, H.A.; COSTA, M.A.; SANTOS-FILHO, B.G. Aspectos fisiológicos da germinação e da qualidade de plântulas de Schizolobium amazonicum em resposta á escarificação das 
sementes em lixa e água quente. Revista

Árvore, Viçosa, v.35, n.4, p.791-800, 2011.

SILVA, P.E.M.; SANTIAGO, E.F.;

DALOSO, D.M.; SILVA, E.M.; SILVA, J.O.

Quebra de dormência em sementes de

Sesbania virgata (Cav.) Pers. IDESIA

(Chile), v.29, n. 2, p. 39-45, 2011.

http://www.scielo.cl/pdf/idesia/v29n2/art05.p

df

VIEIRA, I.G.; FERNANDES, G.D. Métodos

de Quebra de Dormência de Sementes.

Piracicaba: IPEF-LCF/ESALQ/USP,

Informativo Sementes IPEF, 1997. http://www.ipef.br/tecsementes/dormencia.as

$\mathrm{p}$

ZAIDAN, L.B.P.; BARBEDO, C.J. Quebra

de dormência em sementes. In: FERREIRA, A. G; BORGHETTI, F. Germinação: do básico ao aplicado. Porto Alegre: Artmed, 2004. p. 135-148.

ZANON, A.; CARPANEZZI, A.A.;

FOWLER, J.A.P. Germinação em laboratório e armazenamento de sementes de TarumãBranco (Citharexylum myrianthum CHAM.). Colombo-PR, Boletim de Pesquisa

Florestal, n. 35, p.75-82, 1997. 